\title{
Impact of wind turbine sound on general health, sleep disturbance and annoyance of workers: a pilot- study in Manjil wind farm, Iran
}

\author{
Milad Abbasi ${ }^{1}$, Mohammad Reza Monazzam" ${ }^{1 *}$, Arash Akbarzadeh², Seyyed Abolfazl Zakerian ${ }^{1}$ \\ and Mohammad Hossein Ebrahimi ${ }^{3}$
}

\begin{abstract}
Background: The wind turbine's sound seems to have a proportional effect on health of people living near to wind farms. This study aimed to investigate the effect of noise emitted from wind turbines on general health, sleep and annoyance among workers of manjil wind farm, Iran.

Materials and methods: A total number of 53 workers took part in this study. Based on the type of job, they were categorized into three groups of maintenance, security and office staff. The persons' exposure at each job-related group was measured by eight-hour equivalent sound level (LAeq, 8 h). A Noise annoyance scale, Epworth sleepiness scale and 28-item general health questionnaire was used for gathering data from workers. The data were analyzed through Multivariate Analysis of variance (MANOVA) test, Pillai's Trace test, Paired comparisons analysis and Multivariate regression test were used in the $\mathrm{R}$ software.

Results and discussion: The results showed that, response variables (annoyance, sleep disturbance and health) were significantly different between job groups. The results also indicated that sleep disturbance as well as noise exposure had a significant effect on general health. Noise annoyance and distance from wind turbines could significantly explain about 44.5 and $34.2 \%$ of the variance in sleep disturbance and worker's general health, respectively. General health was significantly different in different age groups while age had no significant impact on sleep disturbance. The results were reverse for distance because it had no significant impact on health, but sleep disturbance was significantly affected.

Conclusions: We came to this conclusion that wind turbines noise can directly impact on annoyance, sleep and health. This type of energy generation can have potential health risks for wind farm workers. However, further research is needed to confirm the results of this study.
\end{abstract}

Keywords: Noise annoyance, Sleep disturbance, General health, Wind turbine noise

\section{Background}

Wind energy compared to the other forms of traditional energy generation has fewer health effects and for this reason has positive health benefits [1]. However, compared with the health effects caused by unclean forms of traditional electricity generation, renewable energy generation is related to fewer adverse health effects [2]. Wind turbines generate noise that can be classified into

\footnotetext{
* Correspondence: esmaeelm@sina.tums.ac.ir

'Department of Occupational Health Engineering, School of Public Health,

Tehran University of Medical Sciences, Tehran, Iran

Full list of author information is available at the end of the article
}

a mechanical noise which is produced from the rotor or gearbox and an aerodynamic noise which is generated by turbulent wind flow near the wind turbine blades [3]. Wind turbine noise has remarkable audible Characteristics such as low frequency noise, amplitude modulation, impulsive and tonal Nature [4]. The adverse health effects of wind turbine noise on people can be categorized into the three groups such as Subjective effects (including annoyance, nuisance and dissatisfaction), Interference with activities (such as speech, sleep and learning) and Physiological effects (such as anxiety, tinnitus or hearing loss) [5]. One of the principal human responses 
to audible infrasound is an annoyance [5]. In the Pederson study (2007) except for annoyance, there was no direct adverse health effects associated with wind turbine noise. Pedersen showed that sleep problems and feelings of discomfort could be a secondary effect of the noise exposure that was related to noise annoyance [6]. Leventhall [7] concluded that wind turbine noise as a low frequency sound could have adverse effects on person's health and cause sleep disorder. Noise annoyance can be one of the influencing factors for sleep disorder as they have reciprocal effects on sleep quality $[8,9]$. According to the World Health Organization, noise annoyance has detrimental effects on health-related quality of life [10].

Wind Turbine Syndrome (WTS) is the clinical term for the collection of symptoms such as sleep disorders, headaches, tinnitus, nausea, irritability, loss of memory and concentration, nervousness, rapid heart rate, blood pressure, weight changes, abnormal heartbeat rhythms, mood problems, fatigue and depression experienced by many people living close to industrial wind turbines [11]. As a Multivariate approach, Bakker et al. [8] introduced a structural model that presented among exposure to wind turbine noise, psychological health, annoyance and sleep disturbance, as shown in Fig. 1.

Wind turbine noise can affect annoyance, sleep and health, and any disorder in these factors can amplify the sound exposure effects in the people living close to wind turbines. The effect of the noise exposure on the annoyance, sleep disturbance and health of the people living near to wind farms and their mutual effects on each other was studied in various places around the world and there is a comprehensive literature in this area [6-8], but, so far no study has been conducted to investigate these relations among wind farm workers. Due to the higher noise exposure in workers of wind power plant, as well as the longterm noise exposure, their health and sleep are roughly at the risk of adverse effects related to wind turbine noise. Thus, this study aimed to investigate the relation between exposure to the wind turbine noise and

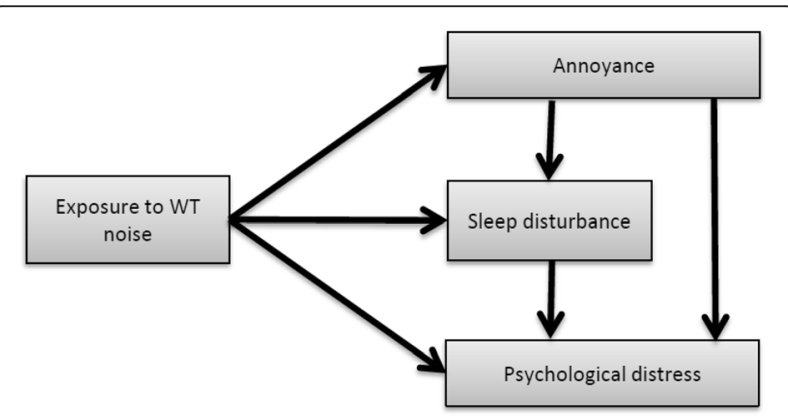

Fig. 1 Structural model with noise exposure, annoyance, sleep disturbance and psychological distress annoyance, sleep disturbance and general health of Manjil wind farm workers.

\section{Materials and methods Study area}

This study was conducted in Manjil wind farm, Gilan, Iran and involved 53 voluntary workers of this wind power plant. Due to the mountainous topography and constant high wind speed in the Manjil district, this area is well-known for its wind energy utilization. This wind farm by 2009 used 171 NEG Micon and Vestas turbines with capacities ranging from 300 to $660 \mathrm{~kW}$. The average wind speed in Manjil is approximately $14 \mathrm{~m} / \mathrm{s}$ (at $40 \mathrm{~m}$ above ground).

\section{Population study}

In this study, according to the distance from wind turbines and job similarities/differences, participants were categorized into three groups including; maintenance, security and administrative staffs. The maintenance workers repair and regulate wind turbines. In some cases, in the turbine trunk and in the vicinity of the turbine rotor, they are exposed to the extremely high level of noise.

The security staff has a further distance from the turbines compared to the maintenance workers. Official personnel are in an office building and due to farther distance from the turbines and insertion loss of barriers such as walls, windows, etc. they receives low level of noise compared to the other job groups.

\section{Sound measurement}

The exposure level of employees at each job group to wind turbine sound was measured by eight-hour equivalent sound level (LAeq, 8 h) based on ISO 9612:2009 [12]. For this aim noise measurement was accomplished in 5, 5 and 2 locations for repairing, security, and official groups, respectively. For generalizing the results of exposure in various occupations, similarity of operations were considered. To achieve information about the features of sound generated by wind turbines, frequency analysis was performed in octave band using a calibrated sound level meter analyzer model TES 1358.

\section{Questionnaires}

A questionnaire was designed to gather demographic data and employees' background information such as age, Job tenure, Shiftwork type, education level, etc. moreover, a 28-item General Health Questionnaire (GHQ-28) was used to indicate psychological well-being and detect psychiatric morbidity. Information about Subjective noise annoyance and individuals' sleep disorder were collected by noise annoyance scale and Epworth Sleepiness Scale (ESS), respectively. 
The 28-item General Health Questionnaire (GHQ-28) has four sub-scales including: somatic symptoms, anxiety and insomnia, social dysfunction and depression. This questionnaire contains 24 questions with a threepoint Likert scale $(0=$ Never, $3=$ much more than usual). The total possible score on the GHQ 28 ranges from 0 to 84 , where lower score indicates better psychological well-being. Reliability and validity of this questionnaire were approved by Goldberg [13]. Noise annoyance was determined based on the "Acoustics-Assessment of noise annoyance by means of social and socio-acoustic surveys" questionnaire which is provided in ISO/TS 15666 standard [14]. This scale included Likert items (0-10) with a high score indicating a high level of annoyance.

The EES contains 8 questions that ask people to rate, on a 4-point scale (0-3) their usual changes of dozing off or falling asleep in 8 different situations or activity. Most people engage in this 8 different situations or activity as part of their daily lives, although not necessarily every day. The total EES score is the sum of 8 itemsscores and can range between 0 and 24. The higher the score, the higher the person's level of daytime sleepiness would be. A number in the range of 10-24 is recognized abnormal (high sleepiness). The ESS has a global reliability and validity assessed by Cronbach's alpha in the range of 73 to $88 \%$ [15].

\section{Statistical analysis}

In the last stage, the collected data were analyzed using $\mathrm{R}$ software. The Multivariate Analysis of variance (MANOVA) test was used to investigate significant differences in response variables such as sleep disturbance, annoyance and general health between noise exposure levels and various groups of age and work experience. The Pillai's Trace test was done to examine the effects of research factors on response variables. The Paired comparisons of significant effects were conducted by Scheffe's post hoc test. Multivariate regression test with Forward method was used to examine the influence of sleep disturbance, distance, noise annoyance, LAeq and age on the general health. Comparison of sleep disturbance and general health between different age groups, noise annoyance groups and various distances was done through MANOVA test.

\section{Results}

Based on the results of this study, the values of $8 \mathrm{~h}$ equivalent noise level in A network for maintenance workers, security and office staff were equal to 83.66 and $60 \mathrm{~dB}$, respectively. A total number of 53 employees of Manjil Wind Farm participated in this study. The mean (SD) age and work experience of the participants were obtained 30.8 (5.9) and 14.1 (5.5) years, respectively. Descriptive statistics of participants according to occupational groups are presented in Table 1.

The average (SD) subjects' general health, noise annoyance, sleep disturbance among all of the participants were obtained 23.6 (6.5), 6 (2.5) and 7.3 (3.1), respectively. As shown in Table 2, among all job groups, maintenance workers had more annoyance, sleep disturbance and general health. On other hand, in individuals with more than 19 years of job experience and individuals with more than 41 years of old had the least amount of noise annoyance, sleep disturbance and general health. Mean (SD) of subjects' general health, noise annoyance, sleep disturbance according to demographic and background variables are presented in Table 2 .

After a preliminary review of data, response variables between different age, work experience and noise exposure group there was no extreme outlier. On the other hand, review of the Minor outlier observations showed accuracy in data. The Multivariate Analysis Of Variance (MANOVA) test was used to investigate significant differences in response variables such as sleep disturbance, annoyance and general health between the three noise exposure levels and various groups of age and work experience. Bartlett's Test of Sphericity revealed that there is a sufficient correlation between the dependent variables for performing the MANOVA (Chi-Square $=156$. $26, P<0.001)$. The hypothesis of equality of observed covariance matrices of the dependent variables, across groups was tested through Box's $M$ test. The test result indicated that, equality of covariance matrices of dependent variables was rejected among various levels of the

Table 1 Descriptive statistics of participants according to occupational

\begin{tabular}{|c|c|c|c|c|}
\hline & Total & Repairman & Security & Official staff \\
\hline distance from wind (m) & & $0-50$ & $50-100$ & $\geq 150$ \\
\hline Number of participants & 53 & 22 & 17 & 14 \\
\hline Percent (\%) & 100 & 41.5 & 32 & 26.5 \\
\hline Mean(SD) of age (year) & $38.1(5.9)$ & $40.2(6.7)$ & $37.5(3.8)$ & $35.4(6)$ \\
\hline Mean(SD) of experience (year) & $14.1(5.5)$ & 16.6(5.5) & 13.2(3.8) & 11.4(6.1) \\
\hline$\ldots<$ diploma & 12 & 4 & 6 & 2 \\
\hline diploma $\leq .$. & 14 & 18 & 11 & 12 \\
\hline
\end{tabular}


Table 2 General health, noise annoyance and sleep disturbance results in terms of job groups, age and experience

\begin{tabular}{|c|c|c|c|c|c|}
\hline & & & General health & Noise annoyance & Sleep disturbance \\
\hline \multirow[t]{10}{*}{ Mean.(SD) } & Total & & $23.6(6.5)$ & $6(2.5)$ & $7.3(3.1)$ \\
\hline & Occupational group & Repairman & $27.1(6.6)$ & $8.4(1)$ & $10.5(1.7)$ \\
\hline & & Security & $22.3(4.3)$ & $5.8(0.9)$ & $6(1.4)$ \\
\hline & & Official staff & 19.2(5.5) & 2.6(1.3) & $4(0.9)$ \\
\hline & Age & $\ldots<36$ & 21.6(5.3) & $4.9(2.3)$ & $6(2.4)$ \\
\hline & & $36-41$ & $22.3(5.1)$ & $3.6(2.5)$ & $7.5(3)$ \\
\hline & & $41<\ldots$ & $30.2(7.3)$ & $8.2(2)$ & $10.2(3.2)$ \\
\hline & Experience & $\ldots<12$ & 19.6(4.5) & $4.9(2.2)$ & $5.6(2.4)$ \\
\hline & & $12-19$ & $24(5.1)$ & $6.2(2.4)$ & $7.4(2.8)$ \\
\hline & & $19<\ldots$ & 29.9(7.3) & $8.1(1.9)$ & $10.1(3)$ \\
\hline
\end{tabular}

independent variable. Thus, Pillai's Trace test was used to study the effects of independent factors on general health, sleep and annoyance. Pillai's Trace test results showed that, response variables were significantly different between three groups of noise exposure such that, noise exposure was able to explain $59 \%$ of variances for response variables (Pillai's $F(6,90)=21.39, P<0.001$, Partial Eta ${ }^{2}=0.59$ ). Age had a significant multivariate effect on response variables and could explain about
$19 \%$ of the variance of the dependent variables (Pillai's F $(6,90)=3.58, P=0.003$, Partial $\left.\mathrm{Eta}^{2}=0.19\right)$. Response variables had no significant difference between three groups of work experience (Pillai's Trace $=0.16$, NS, Partial $\mathrm{Eta}^{2}=0.08$ ). Assumption of equality of variances between all of response variables was proven by Levene's test. Analysis of variance was performed to investigate the effect of noise exposure and age on three dependent variables separately. As shown in Table 3,

Table 3 Tests of between-subjects effects table

\begin{tabular}{|c|c|c|c|c|c|c|c|}
\hline Source & Dependent variable & Type III sum of squares & Df & Mean square & $\mathrm{F}$ & Sig. & Partial Eta squared \\
\hline \multirow[t]{3}{*}{ Corrected model } & Noise annoyance & $303.023^{a}$ & 6 & 50.504 & 54.439 & .000 & .877 \\
\hline & Sleep disturbance & $448.281^{b}$ & 6 & 74.714 & 44.986 & .000 & .854 \\
\hline & General health & $1123.511^{c}$ & 6 & 187.252 & 7.838 & .000 & .506 \\
\hline \multirow[t]{3}{*}{ Intercept } & Noise annoyance & 1496.806 & 1 & 1496.806 & 1613.444 & .000 & .972 \\
\hline & Sleep disturbance & 2258.366 & 1 & 2258.366 & 1359.786 & .000 & .967 \\
\hline & General health & 25150.229 & 1 & 25150.229 & 1052.750 & .000 & .958 \\
\hline \multirow[t]{3}{*}{ LAeq } & Noise annoyance & 211.283 & 2 & 105.642 & 113.874 & .000 & .832 \\
\hline & Sleep disturbance & 283.355 & 2 & 141.677 & 85.305 & .000 & .788 \\
\hline & General health & 224.427 & 2 & 112.213 & 4.697 & .014 & .170 \\
\hline \multirow[t]{3}{*}{ Age } & Noise annoyance & 10.732 & 2 & 5.366 & 5.784 & .006 & .201 \\
\hline & Sleep disturbance & 17.339 & 2 & 8.670 & 5.220 & .009 & .185 \\
\hline & General health & 140.418 & 2 & 70.209 & 2.939 & .063 & .113 \\
\hline \multirow[t]{3}{*}{ Error } & Noise annoyance & 42.675 & 46 & .928 & & & \\
\hline & Sleep disturbance & 76.398 & 46 & 1.661 & & & \\
\hline & General health & 1098.942 & 46 & 23.890 & & & \\
\hline \multirow[t]{3}{*}{ Total } & Noise annoyance & 2302.000 & 53 & & & & \\
\hline & Sleep disturbance & 3424.000 & 53 & & & & \\
\hline & General health & 31798.000 & 53 & & & & \\
\hline \multirow[t]{3}{*}{ Corrected total } & Noise annoyance & 345.698 & 52 & & & & \\
\hline & Sleep disturbance & 524.679 & 52 & & & & \\
\hline & General health & 2222.453 & 52 & & & & \\
\hline
\end{tabular}

${ }^{\mathrm{a}} \mathrm{R}$ Squared $=.877$ (Adjusted R Squared $\left.=.860\right)$

${ }^{\mathrm{b}} \mathrm{R}$ Squared $=.854$ (Adjusted R Squared $=.835$ )

${ }^{\mathrm{C}} \mathrm{R}$ Squared $=.506$ (Adjusted R Squared $=.441$ ) 
noise annoyance was significantly different between three groups of noise exposure $(\mathrm{F}(2,46)=113.87, P<0.001$, Partial $\left.\mathrm{Eta}^{2}=0.83\right)$. Noise exposure groups had a significant effect on sleep disturbance $(\mathrm{F}(2,46)=85.31$, $P<0.001$, Partial $\left.\mathrm{Eta}^{2}=0.79\right)$. Finally, mean of general health among the three exposed groups was not equal and had significant difference between three groups of noise exposure $\left(\mathrm{F}(2,46)=4.69, P=0.01\right.$, Partial $\mathrm{Eta}^{2}=$ $0.17)$. Moreover, noise annoyance was significantly different between age groups $(F(2,46)=5$. $78, P<0.01$, Partial $\mathrm{Eta}^{2}=0.2$ ), But general health had no significant difference between different age groups ( $F(2,46)$ $=2.9$, NS, Partial $\left.\mathrm{Eta}^{2}=0.11\right)$. Age had a significant effect on sleep disorders $(F(2,46)=5.22, P<0.01$, Partial Eta2 $=0.18)$. As shown in Table 3, According to the Adjusted $\mathrm{R}$ Squared, It is notable that, noise annoyance, sleep disturbance and general health was able to explain $86,83.5$ and $44.1 \%$ of variations of model, respectively.

Scheffe's post hoc test was used to make pairwise comparisons of significant effects with bonferroni method. The pairwise comparison results revealed a significant difference in noise annoyance and sleep disturbance between all groups of age. As well as, pairwise comparisons of annoyance and sleep disorder showed significant differences between noise exposure groups, while, general health had significant differences only between two groups of noise exposure including $83 \mathrm{~dB}$ with $66 \mathrm{~dB}$ and $83 \mathrm{~dB}$ with $60 \mathrm{~dB}$. These results are obvious in the estimated marginal means charts. As shown in Figs. 2, 3 and 4. The results of the estimated marginal means for each of the three response variables showed that as age and noise exposure increase then annoyance and sleep disturbance increase, as well as health effects decrease for participants that was between lower than 36 and 36-41 years old.

Multivariate regression analysis (due to forward method) was used to study the effects of sleep disturbance, distance

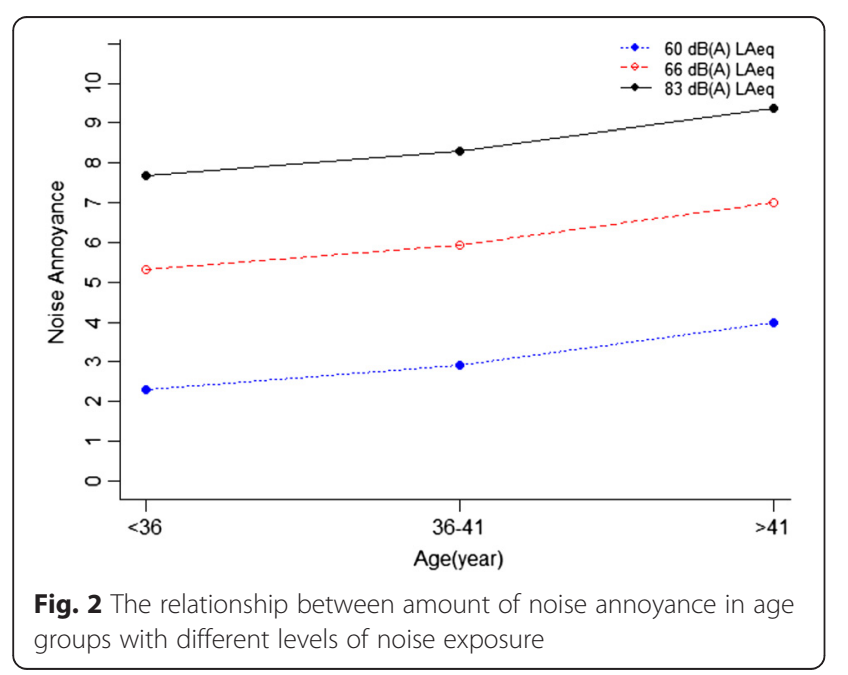

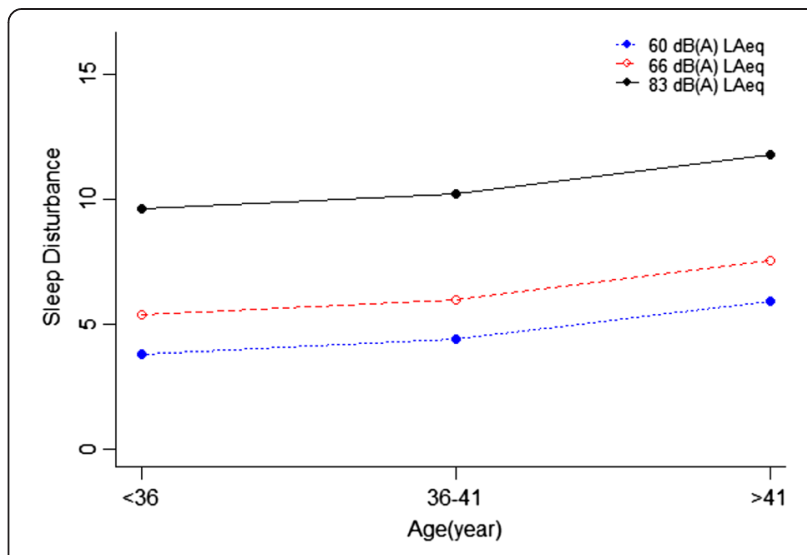

Fig. 3 The relationship between amounts of sleep disturbance in age groups with different levels of noise exposure

from wind turbines, noise annoyance, noise exposure (LAeq, $8 \mathrm{~h}$ ) and age on general health. The results showed that sleep disturbance and noise exposure had a significant effect on general health $(\mathrm{F}(2,50)=40.99, P<0.001)$ and they can explain $61.2 \%$ of changes in response variable. The effect of sleep disturbance and noise exposure on participants' health was 2.62 and -0.39 , respectively. The results of multivariate regression test have obtained in Table 4.

As well as Multivariate analysis of variance (MANOVA) was used to examine the influence of age, noise annoyance and distance from wind turbines on the sleep disturbance and general health. The result of Bartlett's Test of Sphericity showed a significant Correlation between response variables (Chi-Square $=78.72, P<0.001$ ). on the other hand, Box's $M$ test results showed that, the hypothesis of equality of covariance matrices of dependent variables among various levels of the independent variables

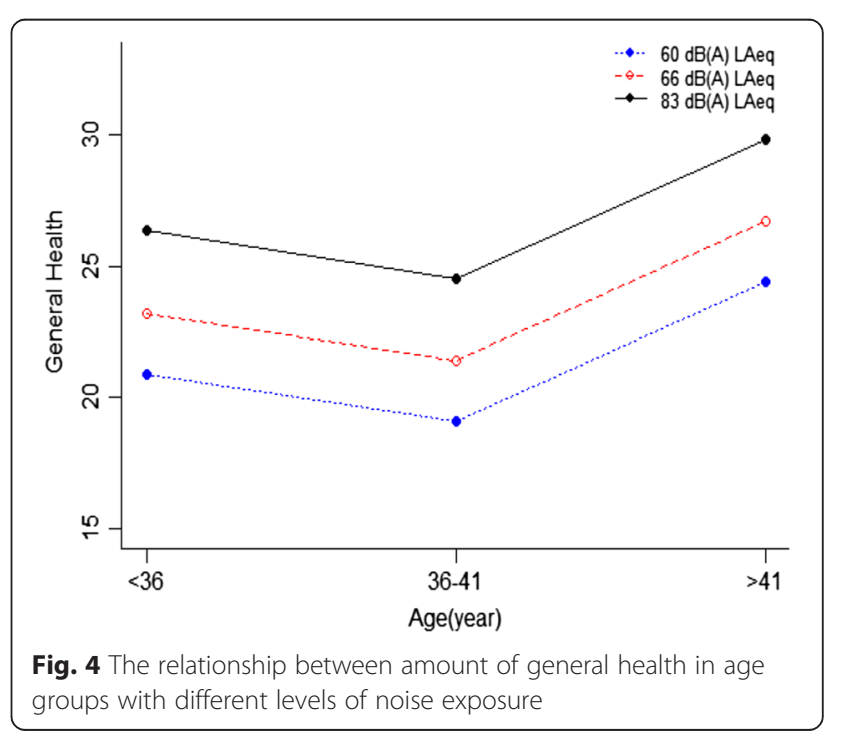


Table 4 Effects of sleep disturbance, distance from wind turbines, noise annoyance, noise exposure and age on general health

\begin{tabular}{|c|c|c|c|c|c|c|c|c|c|}
\hline \multirow{2}{*}{$\begin{array}{l}\text { Dependent } \\
\text { variables }\end{array}$} & \multicolumn{2}{|c|}{ Model compatibility } & \multicolumn{7}{|c|}{ Model coefficients } \\
\hline & $\bar{F}$ & P-value & $B$ & Std. error & Beta & $\mathrm{T}$ & P-value & $\mathrm{R}$ & $R^{2}$ \\
\hline Constant & 40.99 & 0.001 & 32.4 & 6.34 & - & $* 5.11$ & 0.001 & 0.79 & 0.62 \\
\hline Sleep disturbance & & & 2.62 & 0.39 & 1.27 & *6.78 & 0.001 & & \\
\hline LAeq & & & -0.39 & 0.12 & -0.61 & *-3.23 & 0.002 & & \\
\hline
\end{tabular}

*Significant at the 0.05 level

were established (Box's $M=15.05, P=0.2$ ). Thus, Wilks' Lambda test was carried out to study the effects of age, noise annoyance and distance from wind turbines on the sleep disturbance and general health. The result of Wilks' Lambda test showed that noise annoyance and distance from wind turbines could significantly explain about $44.5 \%,\left(\mathrm{~F}(18,76)=3.39, P<0.001\right.$, Partial $\left.\mathrm{Eta}^{2}=0.445\right)$ and $34.2 \%$ of the variance in response variables, $(\mathrm{F}(4,76)=9.86$, $P<0.001$, Partial $\mathrm{Eta}^{2}=0.342$ ), respectively. Age had a significant multivariate effect on response variables so that could explain approximately about $11.6 \%$ of variance in the dependent variables $(F(4,76)=3.58, P=0.04$, Partial $\mathrm{Eta}^{2}=0.116$ ). Assumption of equality of variances in all response variables was proven by Levene test. The results of Between-Subjects analysis showed that noise annoyance had a significant effect on sleep disturbance (F $(9,39)=7.22, \quad P<0.001, \quad$ Partial $\left.\mathrm{Eta}^{2}=0.625\right)$ and general health was significantly different between groups of noise annoyance $(F(9,39)=3.02, P=0.008$, Partial $\left.\mathrm{Eta}^{2}=0.41\right)$. The results of Analysis of variance for effect of age on two response variables showed that general health was significantly different in three age groups $\left(\mathrm{F}(2,39)=3.44, \mathrm{P}=0.04\right.$, Partial $\left.\mathrm{Eta}^{2}=0.15\right)$ and age had no significant impact on sleep disturbance. The results were reverse for distance because it had no significant impact on health $\left(\mathrm{F}(2,39)=1.27\right.$, NS, Partial $\mathrm{Eta}^{2}=$ $0.06)$, but sleep disturbance was significantly affected $\left(\mathrm{F}(2,39)=23.9, P<0.001\right.$, Partial $\left.^{\mathrm{E} t a}{ }^{2}=0.55\right)$. According to adjusted $\mathrm{R}$ squared, sleep disturbance and health explained, 92.7 and $55.7 \%$ of Changes in Model, respectively. The results are shown in Table 5 .

Scheffe's post hoc test was used to do pairwise comparisons of significant effects. Based on health survey data, the group with the greatest noise annoyance showed a significant difference with other groups of noise annoyance. The result of sleep disorders was the same as health and generally, in all noise annoyance groups with more than 5 score there was a significant difference. General health had significant differences only between two groups of age, including age group with more than 41 years of old and group with less than 36 years old, as well as between

Table $\mathbf{5}$ Tests of between-subjects effects table

\begin{tabular}{|c|c|c|c|c|c|c|c|}
\hline Source & Dependent variable & Type III sum of squares & Df & Mean square & $\mathrm{F}$ & Sig. & Partial Eta squared \\
\hline \multirow[t]{2}{*}{ Corrected model } & General health & $1484.529^{a}$ & 13 & 114.195 & 6.035 & .000 & .668 \\
\hline & Sleep disturbance & $495.787^{b}$ & 13 & 38.137 & 51.480 & .000 & .945 \\
\hline \multirow[t]{2}{*}{ Intercept } & General health & 19176.819 & 1 & 19176.819 & 1013.513 & .000 & .963 \\
\hline & Sleep disturbance & 1693.626 & 1 & 1693.626 & 2286.150 & .000 & .983 \\
\hline \multirow[t]{2}{*}{ Noise annoyance } & General health & 514.284 & 9 & 57.143 & 3.020 & .008 & .411 \\
\hline & Sleep disturbance & 48.170 & 9 & 5.352 & 7.225 & .000 & .625 \\
\hline \multirow[t]{2}{*}{ Age } & General health & 130.243 & 2 & 65.121 & 3.442 & .042 & .150 \\
\hline & Sleep disturbance & 4.163 & 2 & 2.081 & 2.810 & .072 & .126 \\
\hline \multirow[t]{2}{*}{ Distance } & General health & 48.213 & 2 & 24.106 & 1.274 & .291 & .061 \\
\hline & Sleep disturbance & 35.373 & 2 & 17.687 & 23.874 & .000 & .550 \\
\hline \multirow[t]{2}{*}{ Error } & General health & 737.924 & 39 & 18.921 & & & \\
\hline & Sleep disturbance & 28.892 & 39 & .741 & & & \\
\hline \multirow[t]{2}{*}{ Total } & General health & 31798.000 & 53 & & & & \\
\hline & Sleep disturbance & 3424.000 & 53 & & & & \\
\hline \multirow[t]{2}{*}{ Corrected total } & General health & 2222.453 & 52 & & & & \\
\hline & Sleep disturbance & 524.679 & 52 & & & & \\
\hline
\end{tabular}


group with more than 41 and group with 36-41 years of old. Finally, sleep disturbance among all of pairwise comparisons between groups of distance from wind turbine noise was statistically significant.

\section{Discussion}

Noise annoyance

The results of this study showed that exposure to noise from wind turbine had a statistically significant effect on annoyance of exposed workers and based on Adjusted R Squared, annoyance could justify $86 \%$ of model Variations. Regardless of the type of noise source, this finding is in accordance with other study [16, 17]. Janssen et al. [18] declared that noise from wind turbines is more annoying than environmental sources such as road and rail traffic noise. One of the characteristics of wind turbine noise like low frequency nature is the reason that wind turbine noise can cause annoyance [19]. In the present study, there was a linear relation between noise exposure and noise annoyance, and workers who had higher noise exposure experienced higher level of annoyance. This result is consistent with Bakker et al. [8] study, which was accomplished among people who lived near to wind farms. They reported that the level of annoyance depended on the level of their noise exposure, a higher exposure increased the possibility of being annoyed $[6,8]$. The visibility of turbines had negative impact on the annoyance of residents [20] and in this study office staff that can't see wind turbine, had lower noise annoyance. Shadow flicker is another feature of wind turbine that can cause annoyance in people. Noise exposure and age have an additive effect on annoyance of workers and a simultaneous increase in these two variables can dramatically increase the level of annoyance.

The results showed a significant positive correlation between the noise annoyance and worker's age and the higher the age, the higher noise annoyance. Hearing loss at high frequencies because of aging process can removes the coating effect of background noise to the wind turbines noise [21]. Thus, it can be supposed that older people experience high level of low frequencies noise due to the decrease in the coating effect for background noise, the older people are more sensitive to low frequency noise generated from wind turbines that make them annoyed [22]. Noise sensitivity and economic benefit also have significant impact on annoyance of people living near to wind farm $[8,23]$. Annoyance among people who are more sensitive to noise is higher than insensible people. Workers are considered as economically beneficiaries of wind power plants and previous studies confirmed that beneficiaries have been less annoyed than other [18]. Due to the higher level of workers noise exposure than residents living near to wind farm, we expected the workers to be more annoyed than general population, but our expectation did not come true which could be because of workers economic benefits from wind power plant, as well as, may be explained by the fact that general populations are more sensitive than workers.

\section{Sleep disturbance}

The results of present study showed that, sleep disturbance between noise exposure groups (job groups) and groups with different age had a statistically significant difference. Results were in accordance with Kim et al. [24] study that showed a dose-response relationship between the airplane sound level and sleep quality. In another study (2013) on people living close to wind turbines, a significant association was reported between the distance from turbines and sleep disturbance [25]. Bruck and his colleague (2009) found that low frequency noise was more effective for arising people from deep sleep [26]. In the previous literature, age was introduced as a predictor for sleep [27, 28]. Solet et al. [29] said that impulsive noise causes more sleep disorder than other types of sound. Solet and his colleagues verify the finding of the present study because wind turbine noise has an impulsive nature. Despite, more noise exposure of workers than the general population, sleep disturbance in the current study is less than that reported by people living near to wind farms. It could be due to hiding the truth about their sleep disorders because of fear of punishment by their superiors, Loss of financial interests due to job loss, more knowledge, strength and consistency of the workers compared to the ordinary people. Nissenbaum et al. [30] showed an exposure-response association between the distances from wind turbines and sleep disorder within the distance of $1.4 \mathrm{~km}$ from the industrial turbines. In the near distance from the noise source, people received more noise and dramatically response to that. Contrary to the obvious differences in methods, tools, and materials used, the results of Nissenbaum and the present study both confirmed the dose-response relationship between wind turbine sound exposure and sleep disorder. Akerstedt et al. [31] said that age can cause poorer sleep quality. Dijk and Duffy [32] studied changes in the circadian during the aging process. They declare that changes in the sleep process such as drops in slow-wave sleep and sleep circles, as well as, a reduced strength of the circadian signal promoting sleep in the early morning hours can be associated with agerelated changes in the circadian. Sedative drugs use, having sickness and having a second job can strongly interfere with workers sleep that was not within the scope of the present study.

\section{General health}

The results of this study showed that exposure to the noise generated by wind turbine had a significant effect 
on general health. A significant difference in general health score among various noise exposure levels only was between $83 \mathrm{~dB}$ with $66 \mathrm{~dB}$ and $83 \mathrm{~dB}$ with $60 \mathrm{~dB}$. It can be stated that, exposure to higher levels of noise, can cause more adverse health effects. The turbine vibration is a risk factor that amplifies the sound effects on maintenance workers. As well as, the difference in salary could be one of the roots of differences in perceived effects.

Health decreased in 36-41 years of age could be due to Compatibility with work conditions in this age range. The analysis results showed that age-increasing alone had no effect on health, but, health been adversely affected by simultaneously increasing age and noise exposure. Based on these results, It can be concluded that age strengthen the effect of noise exposure on general health. Krogh et al. study (2011) reported that people living near wind turbines had various health complaints [33], as well as Nissenbaum and his coworkers said that wind turbine noise at different distance had an different severity of adverse effect on the health. Many studies have been done to investigate the impact of noise generated by wind turbine on the health, but there is no clear understanding of the mechanisms of this effect. Several assumed mechanisms are included as nervousness, exposure to low frequency noise, visual impact, noise sensitivity, noise annoyance, sleep disorder, attitude to the sound sources and individual characteristics [34-37]. Noise is clearly identified as a factor of stress and stress may be considered as the possible mechanism through which mental and physical health can be affected by noise [38].

Multivariate regression test results showed that sleep disturbance and noise exposure had a significant effect on general health and they can explain $61.2 \%$ of changes in response variable. The effect of sleep disturbance and noise exposure on participants' health was 2.62 and -0.39 , respectively. Based on the result, we can see that sleep disturbance compared to noise exposure has greater effect on health. Thus, Noise can disturb sleep of exposed people and in this way, effect on their health. Sleep disorders can cause anxiety that is a reason for other adverse health effects in people who live near wind farms [35]. Leventhall [7] said that wind turbine sound may have serious effects on individuals' health and cause sleep disorder. Baker showed a relationship between sleep disturbance and psychological distress. Thus, the wind turbine can effect on health through direct (by generated noise) and indirect (by caused sleep disturbance) mechanism. As well as Multivariate analysis of variance (MANOVA) was used to examine the influence of age, noise annoyance and distance from wind turbines on the sleep disturbance and general health. the result of analysis test showed that noise annoyance had a significant effect on sleep disturbance and general health. The results of Analysis of variance for effect of distance on two response variables showed that distance from wind turbine noise had no significant impact on health, but sleep disturbance was significantly affected by distance. Noise annoyance cause from anxiety and conflict and if it continues to increase, could cause deterioration of the health and welfare [23]. Dratva et al. [39] said that noise annoyance was associated with health related quality of life. It can be claimed that the effect of noise exposure may be mediated through annoyance rather than through a direct exposure effect [39]. Bakker showed that annoyance can lead to sleep disturbance and psychological distress and there was no direct relation between exposure to the sound of wind turbines and sleep disturbance or psychological distress. Annoyance can be considered as a mediator between sound exposure and sleep disturbance, and also between sound exposure and psychological distress [8]. The previous studies reported that there was an interaction between annoyance and psychological distress as well as between annoyance and sleep $[9,40]$. According to the result of this study, distance from wind turbine had no effect on the psychological distress but significantly affect sleep disturbance. It can be said that due to less distance from wind turbines, maintenance workers declare more sleep disturbance that cause more psychological distress.

\section{Conclusion}

We concluded that wind turbine noise can directly impact on annoyance, sleep and health. The severity of the effects of noise on each of these indicators of health is related to general health conditions of people. The poorer health led to the more effects of noise generated by wind turbine on the annoyance, sleep and psychological distress. It is suggested that, pre- employment health assessment must be done for new recruits to eliminate any reinforcing factors for effects of exposure to sound from wind turbine.

\section{Suggestions for further research}

The authors recommend that, future studies in wind power plants, study the effect of wind turbine noise on health, relying on risk factors such as noise sensitivity, Sedative drugs use, visual impact, shadow flicker effects, shift work and job stress.

\section{Competing interests}

The authors declare that they have no competing interests.

\section{Authors' contributions}

All of the authors have the equal contribution. All authors read and approved the final manuscript. 


\section{Acknowledgment}

We gratefully appreciate Manjil power plant staffs for their kind cooperation.

\section{Author details}

'Department of Occupational Health Engineering, School of Public Health, Tehran University of Medical Sciences, Tehran, Iran. ${ }^{2}$ Department of Epidemiology and Biostatistics, School of Public Health, Tehran University of Medical Sciences, Tehran, Iran. ${ }^{3}$ Department of Occupational Health Engineering, School of Public Health, Shahroud University of Medical Sciences, Shahroud, Iran.

Received: 19 February 2015 Accepted: 4 October 2015

Published online: 12 October 2015

\section{References}

1. Dincer I. Renewable energy and sustainable development: a crucial review. Renew Sust Energ Rev. 2002;4:157-75.

2. Markandya A, Wilkinson P. Electricity generation and health. Lancet. 2007;370:979-90.

3. Colby D, Dobie R, Leventhall G, Lipscomb DM, McCunney RJ, Seilo MT, Sondergaard B. Wind Turbine Sound and Health Effects An Expert Panel Review. American and Canadian Wind Energy Associations; 2009

4. Pedersen E, van den Berg F, Bakker R, Bouma J. Response to noise from modern wind farms in The Netherlands. J Acoust Soc Am. 2009;126:634-44.

5. Pedersen E, Waye KP. Wind turbine noise, annoyance and self-reported health and well-being in different living environments. Occup Environ Med. 2007;64:480-6.

6. Pederson E, Persson WK. Perception and annoyance due to wind turbine noise - a dose-response relationship. J Acoust Soc Am. 2007;116:3460-70.

7. Leventhall G, Pelmear P, Benton S. A review of published research on low frequency noise and its effects. London: Report for Department for Environment, Food and Rural Affairs; 2003

8. Bakker RH, Pedersen E, van den Berg GP, Stewart R, Lok W, Bouma J. Impact of wind turbine sound on annoyance, self-reported sleep disturbance and psychological distress. Sci Total Environ. 2012;425:42-51.

9. Abbasi M, Monazzam MA, Akbarzadeh A, Zakerian SA, Ebrahim MH. Investigation of the effects of wind turbine noise annoyance on the sleep disturbance among workers of Manjil wind farm. Health Safety Work. 2015;5:51-63.

10. Berglund B, Lindvall T, Schewela D. Guidelines for community noise. Geneva: World Health Organization; 2000.

11. Pierpont $\mathrm{N}$. Wind turbine syndrome: a report on a natural experiment. Santa Fe: K-Selected Books; 2009.

12. ISO 9612(2009), Acoustics - Determination of occupational noise exposure and estimation of noise-induced hearing impairment. Geneva: International Organization for Standardization; 2009.

13. Goldberg DP, Williams P. The user's guide to the general health questionnaire. BMJ. 1988; 1:439-43.

14. ISO/TS 15666, Acoustics - Assessment of noise annoyance by means of social and socio-acoustic surveys, ISO/TS 15666. International Organization for Standardization; 2003.

15. Murrayw J. Reliability and factor analysis of epworth sleepiness scale. Sleep. 1992;15:376-81.

16. Ali SA. Industrial noise levels and annoyance in Egyp. Appl Acoust. 2011;72:221.

17. Guoging D, Xiaoyi L, Qili L, Yue Z, Lingjiao H. The relationship between urban combined traffic noise and annoyance: an investigation in Dalian, north of China. Sci Total Environ Sci. 2012;432:189-94.

18. Janssen SA, Vos H, Eisses AR, Pedersen E. A comparison between exposureresponse relationships for wind turbine annoyance and annoyance due to other noise source. J Acoust Soc Am. 2011;130:3746-53.

19. Pawlaczyk-łuszczyńska M, Dudarewicz A, Waszkowska M, Śliwińska-kowalska M. Assessment of annoyance from low frequency and broadband noise. Int J Occup Environ Med. 2003;16:337-43.

20. Pedersen $E$, Larsman P. The impact of visual factors on noise annoyance among people living in the vicinity of wind turbines. J Environ Psychol. 2008:28:379-89.

21. Hurtley C. Night noise guidelines for Europe. Copenhagen: WHO Regional Office Europe; 2009.

22. Berglund B, Lindvall T. Guidelines for community noise. Geneva: OMS; 1999.
23. Shepherd D, Welch D, Dirks KN, Mathews R. Exploring the relationship between noise sensitivity, annoyance and health-related quality of life in a sample of adults exposed to environmental noise. Int J Environ Res Public Health. 2010;7:3579-94.

24. Kim SJ, Chai SK, Lee KW, Park JB, Min BM, Kil HG, et al. Exposure-response relationship between aircraft noise and sleep quality: a community-based cross-sectional study. Osong Public Health Res Perspect. 2014;5:108-14.

25. Paller C, Bigelow Ph, Majowicz Sh, Law J, Christidis T. Wind turbine noise, sleep quality, and symptoms of inner ear problems. Toronto (ON): Symposia of the Ontario Research Chairs in Public Policy; 2013. p. 17.

26. Bruck D, Ball M, Thomas I, Rouillard V. How does the pitch and pattern of a signal affect auditory arousal? J Sleep Res. 2009;18:196-203.

27. Leger D, Christian G, Jean Pierre D, Chantal D, Michel P. Prevalence of insomnia in a survey of 12778 adults in France. J Sleep Res. 2000:9:35-42.

28. Abbasi M, Monnazzam MR, Zakerian A, Yousefzadeh A. Effect of wind turbine noise on Workers' sleep disorder: a case study of Manjil wind farm in Northern Iran. Fluctuation Noise Lett. 2015;14:2.

29. Solet JM, Buxton OM, Ellenbogen JM, Wang W, Carballiera A. A evidence-base design meets evidence-base medicine, the sound sleep study. The center for health design. 2011.

30. Nissenbaum MA, Aramini JJ, Hanning CD. Effects of industrial wind turbine noise on sleep and health. Noise Health. 2012;14:237-43.

31. Åkerstedt T, Knutsson A, Theorell T, Alfredsson L, Kecklund G. Sleep disturbances, work stress and work hours. A cross-sectional study. J Psychosom Res. 2002;53:741-8.

32. Dijk D-J, Duffy JF. Circadian regulation of human sleep and age-related changes in its timing. Ann Med. 1999:31:130-40.

33. Carmen MEK, Lorrie G, Nicholas K, Jeff A. WindVOiCe, a self-reporting survey: adverse health effects, industrial wind turbines, and the need for vigilance monitoring. Bull Sci Technol Soc. 2011;31:334-45.

34. Salt AN, Hullar TE. Responses of the ear to low frequency sounds, infrasound and wind turbines. Hear Res. 2010;268:1221.

35. Pedersen E, Hallberg LR, Persson Waye K. Living in the vicinity of wind turbines a grounded theory study. Qual Res Psychol. 2007;1:4963.

36. Knopper LD, Ollson CA. Health effects and wind turbines: A review of the literature. Environ Health. 2011;10:78.

37. Howe B, Principal PE. Low frequency noise and infrasound associated with wind turbine generator systems: a literature review. Ontario: Ministry of the Environment RFP no; 2010.

38. Kryter KD. The effects of noise on man. Orlando: Academic Press. https:// books.google.com/books?id=WXYBQAAQBAJ\&printsec=frontcover\&dq= editions:13WpHJKDYboC.

39. Dratva J, Zemp E, Felber DD, Pierre-Olivier B, Thierry R, Christian S, et al. Impact of road traffic noise annoyance on health-related quality of life: results from a population-based study. Qual Life Res. 2010;19:37-46.

40. Stansfeld S, Clark C. Mental health effects of noise. Noise pollution and health effects. Encycl Environ Health. 2011;13:683-9.

\section{Submit your next manuscript to BioMed Central and take full advantage of:}

- Convenient online submission

- Thorough peer review

- No space constraints or color figure charges

- Immediate publication on acceptance

- Inclusion in PubMed, CAS, Scopus and Google Scholar

- Research which is freely available for redistribution 